\title{
Evolving metabolism of 2,4-dinitrotoluene triggers SOS-independent diversification of host cells
}

\author{
Akkaya, Özlem; Nikel, Pablo I.; Pérez-Pantoja, Danilo; de Lorenzo, Víctor
}

Published in:

Environmental Microbiology

Link to article, DOI:

10.1111/1462-2920.14459

Publication date:

2019

Document Version

Peer reviewed version

Link back to DTU Orbit

Citation (APA):

Akkaya, Ö., Nikel, P. I., Pérez-Pantoja, D., \& de Lorenzo, V. (2019). Evolving metabolism of 2,4-dinitrotoluene triggers SOS-independent diversification of host cells. Environmental Microbiology, 21(1), 314-326.

https://doi.org/10.1111/1462-2920.14459

\section{General rights}

Copyright and moral rights for the publications made accessible in the public portal are retained by the authors and/or other copyright owners and it is a condition of accessing publications that users recognise and abide by the legal requirements associated with these rights.

- Users may download and print one copy of any publication from the public portal for the purpose of private study or research.

- You may not further distribute the material or use it for any profit-making activity or commercial gain

- You may freely distribute the URL identifying the publication in the public portal 


\title{
Evolving metabolism of 2,4-dinitrotoluene triggers SOS-independent diversification of host cells
}

\author{
by
}

Özlem Akkaya ${ }^{1,4}$, Pablo I. Nikel2 ${ }^{2}$ Danilo Pérez-Pantoja ${ }^{3^{*}}$, and Víctor de Lorenzo ${ }^{4^{*}}$

${ }^{1}$ Department of Molecular Biology and Genetics, Gebze Technical University, Kocaeli, Turkey, ${ }^{2}$ The Novo Nordisk Foundation Center for Biosustainability, Technical University of Denmark, 2800 Kgs Lyngby, Denmark, 3Universidad Tecnológica Metropolitana, Ignacio Valdivieso 2409, San Joaquín, Santiago, Chile, ${ }^{4}$ Centro Nacional de Biotecnología-CSIC, Campus de Cantoblanco, Madrid 28049, Spain

Running title: Stress-induced mutagenesis by DNT

Keywords: Biodegradation, stress-induced mutagenesis, RpoS, nitroaromatic compounds, ROS

* Correspondence to: Víctor de Lorenzo

Centro Nacional de Biotecnología-CSIC

Campus de Cantoblanco, Madrid 28049, Spain

Tel.: 34- 9158545 36; Fax: 34-91 5854506

E-mail: vdlorenzo@cnb.csic.es

Danilo Pérez-Pantoja

Programa Institucional de Fomento a la Investigación, Desarrollo e Innovación Universidad Tecnológica Metropolitana

Ignacio Valdivieso 2409, San Joaquín, Santiago, Chile

Tel.: 56- 227877906

E-mail: danilo.perez@utem.cl

This article has been accepted for publication and undergone full peer review but has not been through the copyediting, typesetting, pagination and proofreading process, which may lead to differences between this version and the Version of Record. Please cite this article as doi: 10.1111/1462-2920.14459 


\section{SUMMARY}

The molecular mechanisms behind the mutagenic effect of reactive oxygen species (ROS) released by defective metabolization of xenobiotic 2,4-dinitrotoluene (DNT) by a still-evolving degradation pathway were studied. To this end, the genes required for biodegradation of DNT from Burkholderia cepacia R34 were implanted in Escherichia coli and the effect of catabolizing the nitroaromatic compound monitored with stress-related markers and reporters. Such a proxy of the naturally-occurring scenario faithfully recreated the known accumulation of ROS caused by faulty metabolism of DNT and the ensuing onset of an intense mutagenesis regime. While ROS triggered an oxidative stress response, neither homologous recombination was stimulated nor the $\operatorname{rec} A$ promoter activity increased during DNT catabolism. Analysis of single-nucleotide changes occurring in rpoB during DNT degradation suggested a relaxation of DNA replication fidelity rather than direct damage to DNA. Mutants frequencies were determined in strains defective in either converting DNA damage into mutagenesis or mediating inhibition of mismatch repair through a general stress response. The results revealed that the mutagenic effect of ROS was largely SOS-independent and stemmed instead from stress-induced changes of rpoS functionality. Evolution of novel metabolic properties thus resembles the way sub-lethal antibiotic concentrations stimulate the appearance of novel resistance genes.

Originality-Significance Statement. The question on how bacteria evolve so quickly the capacity to metabolize chemical compounds that have been in the Biosphere for only a short period of time is not only relevant for understanding evolution of biochemical networks, but also for nurturing new pathways of biotechnological interest. Biodegradation of nitroaromatic compounds offers a most advantageous experimental system for tackling the issue, as the process involves adjustment of pre-existing Rieske non-heme iron-dependent oxygenases to the new compounds. Due to the interim, imperfect enzymesubstrate fitting during such an evolution, the corresponding reactions are often uncoupled and prone to generate reactive oxygen species (ROS) with a high mutagenic potential and thus elicit phenotypic expansion. Yet, the specific mechanisms on how metabolically produced ROS translates into genetic diversification are not clear. Although intuitively one would predict mutagenesis to result from misincorporation of 8-oxoguanine to DNA, implantation of the dnt route for degradation of 2,4dinitrotoluene borne by B.cepacia R34 into genetically tractable strains of $E$. coli suggest otherwise: diversification stems predominantly from the reduction of DNA replication fidelity linked to the general stress response governed by rpoS. We entertain that such mechanism could benefit the exploration of the solution space leading to improvements of the host strain to degrade the xenobiotic compound at stake. 


\section{INTRODUCTION}

Environmental pollution due the release of organic xenobiotic compounds has been occurring worldwide since the onset of synthetic chemistry. Nitroaromatic compounds count among the most relevant environmental contaminants, as they are highly persistent and they are liberated into the biosphere almost exclusively by anthropogenic activities (Ju and Parales, 2010; Kovacic and Somanathan, 2014). Nonetheless, microorganisms able to degrade nitro-chemicals can be found in the environment, suggesting that these catabolic abilities have recently evolved in response to such new growth substrates (Ju and Parales, 2010). In many instances a mere inspection of catabolic sequences for such xenobiotic compounds reveals a clear evidence of a recent and still ongoing evolution, often mediated by horizontal gene transfer and point mutations that expand the substrate range of pre-existing enzymes (Ju and Parales, 2010). Biodegradation of 2,4-dinitrotoluene (DNT) provides a conspicuous example of emergence of a catabolic route for a xenobiotic compound. DNT is not found naturally in the environment, but it is generated as an intermediate in 2,4,6-trinitrotoluene (TNT) production after mixing toluene with nitric acid. The widespread use of DNT in manufacturing ammunition, polyurethane foams, and other chemical products has contributed to extensive soil and groundwater pollution. Not surprisingly, DNT-degrading bacteria were first isolated in contaminated surface water near an army ammunition plant (Spanggord et al., 1991). Since then, a number of DNT-degrading strains have been isolated from several contaminated sites around the world and they all appear to use the route for DNT metabolization borne by the archetypal strains Burkholderia sp. DNT and B. cepacia R34. Specifically, DNT catabolism proceeds through an oxidative pathway that begins with the action of two successive oxygenases (removing stepwise the two nitro substituents) and ends yielding nitrite, pyruvate, and propionyl-CoA (Johnson et al., 2002; Fig. 1A). Molecular characterization of the so-called dnt gene cluster in these strains revealed that the pathway is composed of 3 non-contiguous genomic modules that are functionally (but not physically) connected to the oxygenase-encoding genes (Johnson et al., 2002) Fig. 1B).

The phylogenetic relationships of the $d n t$ sequences and the catalytic features of their encoded products indicate that the cluster for DNT dioxygenase was originated by the recruitment of a homologous gene grouping involved in hydroxylation of the naturally-occurring hydrocarbon naphthalene (Suen et al., 1996; Johnson et al., 2002). Yet, inspection of the extant route reveals that the DNT pathway is still in 
the evolutionary process to become an efficient metabolic device. For instance, the coupling between subsequent catalytic steps is not well balanced and accumulation of pathway intermediates-some of them coloured-becomes evident even with the naked eye (Spanggord et al., 1991). Also, the DNT dioxygenase operon lays adjacent to a LysR-type transcriptional factor called DntR. However, this regulator still keeps responsiveness to salicylate, the effector of the precursor naphthalene dioxygenase operon from which DntA has evolved. As a consequence, DntR is not responsive to DNT or any intermediate of the pathway (de Las Heras et al., 2011). Moreover, the DNA sequence of the dnt cluster still carries several transposon remnants and vestigial genes (Johnson et al., 2002). Finally, B. cepacia R34 barely grows on the nitroaromatic substrate (Nishino et al., 2000) and biodegradation occurs at the cost of very high lethality in the population (Perez-Pantoja et al., 2013). The origin of such lethality is endogenous formation of reactive oxygen species (ROS) during the execution of the first step of the route by DNT dioxygenase. Since the ensuing oxidative stress is ultimately converted into DNA mutagenesis, we have argued that similarly to the scenario described for emergence of some antibiotic resistances (Blazquez et al., 2018),stress-induced DNA damage helps cells to diversify genetically and thus to exploring the solution space for improving DNT-metabolization (Perez-Pantoja et al., 2013).

While the phenomenon that starts with ROS production brought about by deficient metabolization of DNT and ends with a high-mutagenesis regime in B. cepacia R34 is well documented (Perez-Pantoja et al., 2013; Akkaya et al., 2018), the molecular mechanisms behind the process are not clear. ROS can react directly with free or DNA-bound nucleotides and generate variants (e.g. 8-oxoguanine) that pair with the wrong partners in the helix and thus generate mutations. But proteins and metabolites can also be damaged by ROS (Krisko and Radman, 2013) and cells may trigger a general stress response that activate error-prone DNA polymerases and relax mismatch repair (Foster, 2005). Given the difficulty to address these mechanistic questions rigorously in the original host of the dnt pathway we have experimentally recreated the metabolic scenario of B. cepacia R34 in E. coli. To this end, the complete $d n t$ pathway was implanted in strains of this surrogate host bearing mutations and/or devices that exposed the different types of stresses undergone by cells during DNT catabolism. The genetic evidence reported below suggests that the bulk of the mutagenic regime turned on by metabolic ROS is not the result of direct damage to DNA but to the RpoS-mediated activity of the error-prone Pol IV DNA polymerase and the concomitant relaxation of the mismatch repair (MMR) mechanism. That redox stress is translated in a general reduction of DNA replication fidelity without triggering a SOS response 
could have advantages for widening the novelty supply rate of the population without compromising overall viability.

\section{RESULTS AND DISCUSSION}

Implantation of a DNT biodegradative pathway in E. coli

The whole set of genes required for complete catabolism of DNT in environmental isolate $B$. cepacia R34 includes three genetic modules: $d n t R-d n t A a b c d, d n t B$ and $d n t D E G$. These were prepared as separate DNA fragments and assembled in the low-copy-number vector pSEVA651 (Fig. 1B) as explained in Experimental procedures. The resulting plasmid, pSEVA_dnt, included the full complement of $d n t$ genes arrayed as a polycistronic construct and expressed under the control of its native $P_{d n t A}$ promoter. Despite the presence of an adjacent $d n t R$ gene, the $P_{d n t A}$ promoter functions constitutively at a low output and is blind to the presence of the pathway substrate, DNT (de Las Heras et al., 2011). The host chosen for heterologous expression of the DNT pathway was E. coli BW25113 (Table 1), the parental strain of the KEIO collection (Baba et al., 2006) of the knockout mutants that were used in this study later on. The functionality of the route in $E$. coli was easily visualized by accumulation of 4-methyl5-nitrocatechol (4M5NC) in cells grown in minimal M9 medium with $0.4 \%$ succinate amended with 0.5 mM DNT. As shown in Fig. 1A, 4M5NC is the product of DNT dioxygenation by the DntA enzymatic complex and the first intermediate of the pathway. Its synthesis tints the cultures with a distinct yellow colour (de Las Heras et al., 2011). The characteristic absorption peak of 4M5NC at $420 \mathrm{~nm}$ could only be observed in cultures of the strain carrying the pSEVA_dnt plasmid upon addition of DNT (Fig. 1C). As a quantitative measure of the DNT degradation activity implanted in $E$. coli BW25113, the consumption of the $0.5 \mathrm{mM}$ DNT present in the culture medium was followed by gas chromatographymass spectrometry. After $24 \mathrm{~h}$ of incubation, E. coli BW25113 (pSEVA_dnt) processed almost $90 \%$ of the aromatic substrate. Expectedly, no substrate consumption was detected in cultures of the strain carrying an empty plasmid. Furthermore, 2-hydroxy-5-methylquinone $(2 \mathrm{H} 5 \mathrm{MQ}$, the metabolic product of the 4M5NC monooxygenase encoded by $d n t B$ ) was detected at a concentration of $0.11 \pm 0.03 \mathrm{mM}$ in supernatants of $E$. coli BW25113 (pSEVA_dnt) cultures added with DNT, but not in control experiments. Taken together, these data confirm expression of the first steps of the DNT pathway in E. coli as well as the unbalance between the different enzymatic activities that leads to accumulation of intermediates. 
This reproduces the state of affairs known in the original host of the route (B. cepacia R34) and accredits the E. coli BW25113 (pSEVA_dnt) setup as a good proxy for inspecting the mechanistic interplay between metabolic stress and evolvability-as addressed in the sections below.

\section{DNT metabolization increases intracellular ROS levels and triggers an oxidative stress response}

In order to inspect formation of intracellular ROS caused by metabolization of DNT, E. coli BW25113 (pSEVA_dnt) cells pregrown in filter-sterilized LB medium were added with $0.5 \mathrm{mM}$ of DNT for $16 \mathrm{~h}$ and then treated with $2^{\prime}, 7^{\prime}$-dichlorodihydrofluorescein diacetate $\left(\mathrm{H}_{2} \mathrm{DCF}-\mathrm{DA}\right)$, a green fluorescent dye that is activated by in vivo reaction with peroxides and hydroperoxides. As a control, we did the same to $E$. coli BW25113 transformed with the insertless vector pSEVA651. After 30 minutes of $\mathrm{H}_{2} \mathrm{DCF}-\mathrm{DA}$ treatment, bacteria were subject to quantitative flow cytometry as explained in Experimental procedures, with the results shown in Fig. 2. In cells lacking the dnt genes, only a minor production of ROS was detected upon addition of DNT to the cultures, even in the absence of any metabolism of the compound. This is logical, given that DNT is itself an aromatic compound that may interfere with membrane function and thus cause some stress in the respiratory chain (Sikkema et al., 1995). The mere presence of the pSEVA_dnt plasmid caused also some residual generation of ROS as detected with $\mathrm{H}_{2} \mathrm{DCF}-\mathrm{DA}$ dye, perhaps due to side, promiscuous reactions of the DntA complex with some aromatic metabolites. Yet, the levels of such background ROS in vivo was insignificant when compared to that built by $E$. coli BW25113 (pSEVA_dnt) cells treated with DNT.

For verifying the production of ROS stemming from DNT metabolism and expose the ensuing physiological consequences, E. coli BW25113 (pSEVA_dnt) was transformed with compatible, lowcopy-number plasmids bearing constructs reporting the appearance of an oxidative stress response. In one case $\left(p_{-} k a t G\right)$, the reporter consisted of a transcriptional fusion between the promoter of the catalase gene and the gene encoding the monomeric super-folder green fluorescent protein (msfGFP), assembled in the kanamycin-resistant $\left(\mathrm{Km}^{\mathrm{R}}\right)$, oriVRK2 vector pSEVA227M (Fig. 3A). In the other case, the reporter plasmid $p_{-}$ahpC bore an equivalent fusion with the promoter of the alkyl hydroperoxide reductase gene. Either the $p \_k a t G$ or the $p \_a h p C$ plasmid was thus transferred to $E$. coli BW25113 (pSEVA_dnt) and the fluorescent readout measured when cultures pregrown in LB medium were exposed to DNT for $16 \mathrm{~h}$. As a positive control, a non-lethal dose of ciprofloxacin (CIP, a fluoroquinolone 
which induces oxidative stress; (Becerra et al., 2003) was used as a control of the reporters' responsiveness to ROS.

The green fluorescence generated by plasmids $p \_k a t G$ and $p \_a h p C$ when cells were treated with either $100 \mathrm{ng} / \mathrm{ml}$ CIP or two different DNT concentrations was quantified by flow cytometry. Fig. 3B shows the fold-change on average fluorescence intensity of CIP or DNT-treated cells normalized to the average fluorescence intensity of control cells incubated without any stressor. As expected, both reporters displayed a clear induction by CIP with a pronounced upregulation of the ahpC promoter. The transcriptional response of the reporters triggered by DNT metabolism was expectedly lower, but clearly noticeable with the $P_{a h p c}-m s f G F P$ fusion. In contrast katG increase was less obvious. As each reporter is specialized in a different type of oxidative stress it could be that the ROS pool resulting from faulty reactions of the DntA dioxygenase with DNT contains a good share alkyl hydroperoxides and less of free hydrogen peroxide. In any case, the data above recognizes in $E$. coli the accumulation of ROS resulting from metabolization of DNT that was observed in B. cepacia R34 (Perez-Pantoja et al., 2013). Furthermore, the results of Fig. 2 and Fig. 3 give proof that such scenario leads to activation of an oxidative stress response.

\section{DNT-metabolization triggers a mutagenic regime in $\mathrm{dnt}^{+} \mathrm{E}$. coli}

Reactive oxygen species are known to react with nucleotides, both as free molecules and as bases inserted in the sequence of nucleic acids (Bolin and Cardozo-Pelaez, 2007) and they also alter the functions of proteins involved in DNA maintenance (Li, 2008; Krisko and Radman, 2013). The predominant effect of such reactions is oxidation of $G$ residues to 8-oxoguanine, the misincorporation of which in DNA typically causes mutations $G \rightarrow T$. But other bases may also be oxidized, thereby generating additional changes, and DNA replication fidelity can be affected as part of a general stress response. To check whether such ROS-driven mutagenesis regime known to occur in $B$. cepacia R34 during metabolization of DNT happened also in the proxy E. coli BW25113 (pSEVA_dnt) cells, a culture of this strain was pregrown in $\mathrm{LB}$ medium up to $\mathrm{OD}_{600}=0.5$, exposed to $0.5 \mathrm{mM}$ DNT for $24 \mathrm{~h}$ and the number of rifampicin resistant (RifR) colonies counted after plating in selective medium with the antibiotic. While the mutant frequencies in the control dnt-minus strain E. coli BW25113 (pSEVA651) added with DNT and in DMSO-treated E. coli BW25113 (pSEVA_dnt) were somewhat moderate $(3.2 \mathrm{x}$ 
$10^{-10}$ and 1,8 $\times 10^{-10}$, respectively), addition of the nitroaromatic substrate to the DNT-metabolizing strain multiplied by $10-15$ fold the frequencies of emergence of RifR CFUs $\left(1,9 \times 10^{-9}\right)$. These data not only sanctioned the surrogate host as a model of the situation in the environmental isolate but also documented that the ROS stemming from DNT metabolism induced a conspicuous mutagenic state. That the 3 main features of the dnt route of $B$. cepacia R34 (unbalance of intermediate metabolites during degradation, intracellular ROS production and acquisition of a genetic diversification regime) could be recreated in $E$. coli, enabled the study of the molecular mechanisms behind this phenomena, as addressed in the sections below.

\section{DNT biodegradation does not activate the SOS response of $E$. coli}

The default mechanism for acquisition of a high mutagenesis regime is connected to the SOS response that follows DNA damage. A gross method for detecting SOS-related phenomena in $E$. coli involves monitoring of changes in homologous recombination frequencies. This is because the RecA protein involved in activation of SOS response by cleaving the LexA repressor of the SOS regulon also promotes homologous pairing and DNA strand exchange, steps important to homologous recombination. In order to inspect the effect of DNT biodegradation on recombination we adopted the method sketched in Fig. 4A-C that measures intrachromosomal reconstitution of a functional lacZ out of two truncated, non-functional alleles (Elez et al., 2007; Lopez et al., 2007). The interrupted lacZ fragments are separated by a 569-bp DNA spacer and they share a 1.3-kb long overlapping region. When recombination occurs, a functional lacZ gene is reassembled. The resulting cells can then grow on minimal medium containing lactose as the sole carbon source. The emergence of $\mathrm{Lac}^{+}$colonies thus allows estimating the frequency of recombination events under various conditions. Again we used CIP as a positive control of the reporter system since this antibiotic is a recognized inducer of SOS response and consequently cells exposed to CIP are known to undergo a boost in recombinogenic activity (Phillips et al., 1987; Lopez and Blazquez, 2009). As shown in Fig. 4D, CIP addition to the control plasmidless strain $E$. coli ME12 (a derivative of $E$. coli BW25113 endowed with the recombination reporting device of Fig. 4A caused a $\sim 5$-fold increase of $\mathrm{Lac}^{+}$colonies (Fig. 4D), which is in the range of the values reported elsewhere (Lopez et al., 2007). For inspecting the effect of DNT metabolism in intra-genomic recombination, E. coli ME12 was separately transformed with pSEVA_dnt and pSEVA651 and challenged with either DNT $(0.5 \mathrm{mM})$ or just DMSO as explained in the Experimental procedures. 
Adequate dilutions of each culture were then plated in M9-lactose and M9-glucose to select for Lac ${ }^{+}$ recombinants vs. total viable population. As shown in Fig. 4D, a moderate increase in $\mathrm{Lac}^{+}$colonies ( 1.7-fold) was detected in both E. coli ME12 (pSEVA_dnt) and E. coli ME12 (pSEVA651) upon exposure to DNT. This indicated that metabolization of the nitroaromatic compound did little to promote recombination events beyond what the mere exposure of DNT or the stress caused by bearing the plasmids could do. This was unexpected, as DNT-metabolizing cells undergo a mutagenic regime while degrading the compound that could be explained through the damage to DNA caused by ROS and the ensuing SOS response. To check whether this was indeed the case, we ran a separate genetic test with dedicated reporter plasmids in which the promoter of the $\operatorname{rec} A$ gene had been fused to a bicistronic GFP-IuxCDABE reporter (Benedetti et al., 2012). Direct DNA damage is translated by the SOS system into activation of the proteolytic activity of RecA which in turn cleaves the LexA repressor that inhibits transcription of the recA promoter and others related to DNA-repair activities (Michel, 2005). For our purposes, the recA promoter region including the LexA binding site was inserted in pSEVA651compatible vector pGLR2 to yield pGLR2-PrecA (Fig. $5 A$ ). This reporter plasmid was introduced into $E$. coli BW25113 (pSEVA_dnt), and DNA damage readout recorded in a qualitative soft-agar diffusion test by exposing the cells to either DNT or norfloxacin (NOR), a well-known inducer of the SOS response (Phillips et al., 1987; Piddock and Wise, 1987). As shown in Fig. 5C, when E. coli BW25113 transformed with plasmids pSEVA651_dnt plus pGLR2-PrecA was exposed to NOR, a band of strong green fluorescence under blue light became evident at the boundary of the growth inhibition halo. In contrast, while growth of the same strain was inhibited by the highest concentration of DNT, no GFP expression signal could be detected under the same conditions (Fig. 5C). The same qualitative pattern could be quantified by measuring the emission of fluorescence in liquid cultures of E. coli BW25113 (pSEVA_dnt + pGLR2- $P_{\text {rec }}$ ) added with either NOR or DNT. As shown in Fig. $5 B$, the fluorescent signal coming from the DNT-added cultures was indistinguishable from those that were not treated at all. This was in sharp contrast with the very high GFP readout of cells amended with the SOS-triggering antibiotic: as shown in Fig. 5B, a non-lethal dose of NOR triggered a 50-fold increase of green fluorescent emission. The clear conclusion of these experiments is that-while inducing a mutagenic state-DNT metabolization did not activate a SOS response in the DNT-degrading E. coli derivative. How can then ROS and oxidative damage be translated into genetic diversification?

rpoB mutations in DNT-exposed and non-exposed E. coli BW25113 (pSEVA_dnt) cells 
To gain an insight on the causes of the SOS-unrelated acquisition of a mutagenic regime by DNTdegrading bacteria we analysed the type of mutations borne in the $r p o B$ gene (encoding the $\beta$ subunit of RNA polymerase) of RifR colonies isolated from cultures of E. coli BW25113 (pSEVA_dnt) treated or not with the nitroaromatic substrate. The rationale of this analysis was to compare the distribution of transitions $(A \Leftrightarrow G, C \Leftrightarrow T)$ and transversions $(A \Leftrightarrow C, A \Leftrightarrow T, C \Leftrightarrow G, G \Leftrightarrow T)$ in mutants spontaneously resistant to rifampicin because of changes in the $r p o B$ vs. mutants after treatment of the DNTmetabolizing strain with the aromatic substrate. The occurrence of 8-oxoguanine in the DNA sequence resulting from oxidation of $G$ residues (whether in solution or already incorporated to the nucleic acid) originates a distinct transversion $G \rightarrow T$, the relative frequency of which in respect to the other possible changes can be considered a proxy of the direct role of ROS on setting a mutagenic regime. On this basis, a sample of 100 RifR clones were collected after plating blank cultures of $E$. coli BW25113 (pSEVA_dnt) grown in LB agar dishes with rifampicin (control sample) and the same with cultures pretreated with $0.5 \mathrm{mM}$ DNT (test sample). The region of $r p o B$ known to account for the resistance phenotype was subject to a PCR reaction with primers rpoB-Fw and rpoB-Rv (see Experimental procedures) and the amplified DNA sequenced. Fig. 6 summarizes the results. Although the sample size was moderate, the trend was clear that changes $G \rightarrow T$ did not take over the distribution of mutations observed in samples not treated with DNT. The background mutation profile has a predominance of GC $\rightarrow$ AT and AT $\rightarrow$ TA changes that are minimally altered in mutants stemming from the treatment with DNT. Therefore, the influence of direct 8-oxoguanine misincorporations in the hypermutation regime of cells metabolizing DNT pattern is small-if existing at all. Given that this is all SOS-independent (see above) we hypothesized that the ROS stemming from flawed DNT degradation could instead relax the default mechanisms for maintaining DNA sequence fidelity. In this way, mutants rates would increase but the distribution of single-nucleotide changes remain the same. Genetic evidence presented below indicated that this was the case.

\section{DNT metabolism elicits an rpoS-mediated general stress response}

If not direct ROS-mediated DNA damage, what could elicit the high frequency of mutations in DNTmetabolizing cells? It has been long known that regardless of the specific challenge, bacteria may increase mutants rates in response to stress for accumulation of mutations that can be beneficial to 
cope with the insult. A wealth of data suggests that such adaptive mutagenesis is a regulated, complex process with the mismatch repair (MMR) system at its core (Li, 2008). The key component of MMR is MutS, which triggers the repair process by recognizing mismatched bases in the DNA helix. As sketched in Fig. 7, ROS induces the RpoS regulon (Dapa et al., 2017), an event that bifurcates in two directions. First, it enhances expression of DNA polymerase IV (Pol IV) encoded by the $\operatorname{din} B$ gene in a fashion that increases upon activation of the recA-mediated SOS response (Galhardo et al., 2009). Pol IV is an error-prone enzyme with the ability to compete and replace the high-fidelity counterparts (Hastings et al., 2010). The transcription of the $\operatorname{din} B$ gene is positively controlled by RpoS (Layton and Foster, 2003) and a substantial portion of stress-induced mutagenesis is indeed mediated by Pol IV. Second, rpoS also increases expression of a small RNA named SdsR, which, in turn, inhibits translation of mutS. In addition, another sRNA (ArcZ) which becomes upregulated under oxidative conditions, both stimulates translation of rpoS and inhibits that of mutL (Chen and Gottesman, 2017). The scheme of Fig. 7 provides a template on which to discern genetically the relative contribution of the SOSdependent and general stress dependent increase of mutagenesis rates in the DNT-degrading strain. To this end, pSEVA_dnt was passed to an isogenic collection of $E$. coli strains derived from $E$. coli BW25113 and carrying separate deletions in recA, rpos and $\operatorname{dinB}$. Two additional SOS-dependent genes ( $u m u C$ and $s u l A$ ) were tested as controls of the recA-dependent route for genetic diversification. Each of the resulting transformants were grown in LB medium with or without DNT and the frequencies of appearance of RifR mutants calculated as before. The results shown in Fig. 8 expose the most plausible mechanism for the observed DNT metabolism-dependent mutagenesis. First, cells lacking rpoS were very virtually blind to the stress, suggesting that the lion's share of the mutations stemmed ultimately from the activity of this alternative sigma factor. Second, the loss of recA allowed a detectable level of stress-triggered mutagenesis to occur. How can this occur if DNT metabolization fails to induce a SOS response at all (see above)?. The response seems to lay in the data with the $\operatorname{din} B$ (Pol IV) strain, the loss of which decreases significantly, but does not abolish the frequency of appearance of RifR colonies. Finally, neither Pol V (one subunit encoded by umuC and involved in fixing translesions and abasic sites) nor sulA (a SOS-dependent inhibitor of cell division and inducer of filamentation and thus possible origin of CFU counting artefacts) had any significant effect in the numbers of RifR mutants. Taken together, the data of Fig. 8 indicated that the mutagenic effect of metabolic ROS caused by faulty reactions during DNT degradation is the combination of MMR inhibition (major component) and the 
action of the error-prone Pol IV DNA polymerase (minor component)-both causes originated in the overproduction of RpoS elicited by oxidative stress as sketched in Fig. 7.

\section{Conclusion}

By recreating the DNT catabolic system of B. cepacia R34 in E. coli, we could dissect the process that translates faulty reactions during metabolism of the aromatic substrate into genetic diversification. The progression from one to the other when the route is placed in the heterologous host fits the general frame of adaptive mutagenesis or stress-induced mutagenesis. The outcome of the process is a more intense exploration of a solution space (at the cost of considerable mortality; Tenaillon et al., 2004) for coping with the original challenge-in this case a suboptimal metabolic pathway. The most remarkably finding is the absence of any detectable SOS response in the mutagenesis pathways provoked by DNT metabolization, indicating that no extensive DNA damage is caused by ROS accumulation stemming from exposure to the nitroaromatic compound. Instead, the effects are largely ruled by the activation of the rpoS regulon upon oxidative stress. As shown above, this translates both in a recA-independent activation of the $\operatorname{din} B$ gene encoding the Pol IV along with the relaxation of MMR through MutS inhibition. The role of other rpoS-dependent DNA polymerases (e.g. Pol II encoded by the polB gene; Dapa et al., 2017) was not explored in this work but may deserve further studies.

The scenario set by the data above is reminiscent of the picture described for sublethal concentrations of $\beta$-lactam antibiotics that cause ROS production and induce Pol IV-dependent mutagenesis in a SOSindependent fashion (Gutierrez et al., 2013). Similarly to what we describe above, it has been proposed that mutagenesis induced by antibiotics activate RpoS via induction of the $\operatorname{din} B$ gene along with a reduction of the DNA-replication fidelity by inhibiting the MMR system of $E$. coli (Blazquez et al., 2018). Such an effect involves SdsR, a RpoS-controlled small RNA, and Hfq which is the RNA chaperone that facilitates the post-transcriptional regulation of mRNAs by sRNAs (Gutierrez et al., 2013). MutS depletion then leads to reduced control of DNA-replication fidelity and increased mutagenesis (Gutierrez et al., 2013; Chen and Gottesman, 2017). Likewise, the stress-induced mutagenesis triggered by ROS during non-efficient metabolization of xenobiotic compounds could push forward the evolution of novel metabolic properties in a similar way as sub-lethal antibiotic concentrations stimulate the appearance of de novo resistances (Kohanski et al., 2010; Gullberg et al., 2011; Andersson and Hughes, 2014). The 
paradoxical outcome of this scenario is that the same evolutionary mechanisms that foster emergence of desirable new pathways for degradation of xenobiotic pollutants (IImjarv et al., 2017) enable the advent of unwelcome strains that scape the action of antibiotics. Finally, it is worth to note that not every species may have the same mechanisms for translating ROS into genetic diversification. In fact, both SOS-triggering direct DNA damage and the onset of a general stress response may co-exist and contribute to the outcome in different proportions depending on the specific host of the process (Blazquez et al., 2018). It is plausible that the greater role of the general stress response reported for $E$. coli above generates a more physiologically tolerable regime while the population diversifies as compared to straight DNA damage. MMR relaxation might enable a prolonged valley of no-fitness-gain (Kessinger and Van Cleve, 2018) while exploring the metabolic solution space and eventual selection of a better functionality. This is likely the case during evolution of new biochemical pathways involving the genetic tuning of many genes.

\section{EXPERIMENTAL PROCEDURES}

\section{Bacterial strains and culture conditions}

Bacterial strains used in this study are listed in Table 1. B. cepacia R34 has been described before as a DNT degrading specimen (Nishino et al., 2000). The following E. coli K-12 strains were used in this

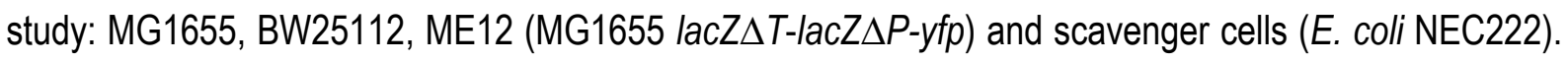
E. coli BW25113 and its mutant derivatives were used to estimate mutants rates as Rif resistant clones. For standard cloning and plasmid propagation, E. coli CC118 and DH5a were used. E. coli cells were grown at $37^{\circ} \mathrm{C}$ in LB medium ( $10 \mathrm{~g} \mathrm{l}^{-1}$ of tryptone, $5 \mathrm{~g} \mathrm{l}^{-1}$ of yeast extract and $5 \mathrm{~g} \mathrm{l}^{-1}$ of NaCl). When required, LB was amended with $0.5 \mathrm{mM}$ or $0.8 \mathrm{mM}$ of DNT from a stock prepared at $0.5 \mathrm{M}$ in dimethyl sulfoxide (DMSO). Antibiotics were added at the following final concentrations whenever needed: ampicillin, $150 \mu \mathrm{g} \mathrm{ml}^{-1}$; chloramphenicol, $30 \mu \mathrm{g} \mathrm{ml}^{-1}$; kanamycin, $50 \mu \mathrm{g} \mathrm{ml}^{-1}$, and gentamicin, $10 \mu \mathrm{g} \mathrm{ml}^{-1}$. All solid media also contained $15 \mathrm{gl}^{-1}$ agar. Other supplements were added when required as follows: 5-bromo-4-chloro-3-indolyl- $\beta$-D-galactopyranoside (X-Gal) and isopropyl- $\beta$-D-thiogalactopyranoside (IPTG) were used at concentrations of $40 \mu \mathrm{g} / \mathrm{ml}$ and $1 \mathrm{mM}$, respectively. $250 \mathrm{ng} / \mathrm{ml}$ of NOR were used for flow cytometry experiments while CIP employed as a control for oxidative stress was added to the cultures at $100 \mathrm{ng} / \mathrm{ml}$. Unless stated otherwise, all generic chemicals and inducers were purchased from 
Sigma-Aldrich Co. (St. Louis, MO). Flow cytometry materials (buffers and calibration beads) were purchased from Miltenyi Biotec $\mathrm{GmbH}$.

\section{Analytical procedures}

Overnight-grown $E$. coli cells were used as the inoculum by diluting them to a starting $\mathrm{OD}_{600}$ of ca. 0.05 . Cells were grown in the same culture medium until they reached an $\mathrm{OD}_{600}$ of $\mathrm{ca} .0 .5$, at which point the cell suspension was split into two 125-ml Erlenmeyer flasks, one culture served as a control experiment and was added with DMSO (the vehicle for DNT), and the other one was amended with DNT (from concentrated solutions in DMSO) to a final concentration of $0.5 \mathrm{mM}$. Cells were aerobically grown overnight at $37^{\circ} \mathrm{C}$ by $24 \mathrm{~h}$ and then removed by centrifugation at $8,000 \times \mathrm{g}$ for $15 \mathrm{~min}$ at $4^{\circ} \mathrm{C}$ and the supernatant kept for analysis of DNT biodegradation intermediates. Metabolites were extracted from the culture supernatants by using $\mathrm{CHCl}_{3}$ or ethyl acetate (de Las Heras et al., 2011). Gas chromatographymass spectrometry analysis for quantification of DNT and $2 \mathrm{H} 5 \mathrm{MQ}$ was performed as indicated previously (Johnson and Spain, 2003). In addition, accumulation of the yellow intermediate 4M5NC was spectrophotometrically quantified by absorbance readings at $420 \mathrm{~nm}$ (de Las Heras et al., 2011).

\section{DNA techniques}

DNA manipulations followed routine laboratory techniques as described by (Sambrook et al., 1989). Plasmid DNA was obtained using the QIAprep Spin Miniprep kit (Qiagen, Inc., Valencia, CA, USA). DNA amplified through the polymerase chain reaction (PCR) was purified with NucleoSpin Extract II (Macherey-Nagel, Düren, Germany). Oligonucleotides were purchased from Sigma-Aldrich Co. (St. Louis, MO, USA). Restriction enzymes were obtained from New England Biolabs Inc. (Ipswich, MA, USA), and T4 DNA ligase was purchased from Roche Applied Science Co. (Indianapolis, IN, USA). To amplify DNA segments by PCR, 50-100 ng of the template indicated in each case was mixed in a $100 \mu \mathrm{l}$ reaction mixture with $50 \mathrm{pmol}$ of each of the primers specified and 2.5 units of Pfu DNA polymerase (Stratagene). Clones were first checked by colony PCR (Sambrook et al., 1989) using 1.25 units Taq DNA polymerase (Roche) and later confirmed by DNA sequencing. Colony PCR was performed using a single colony from a fresh agar plate and transferred directly into the PCR reaction tube. All constructs were verified by DNA sequencing (Secugen SL, Madrid, Spain). 
Construction of a genetic cassette for expression of the complete DNT pathway

The plasmid carrying different parts of the DNT degradation pathway of $B$. cepacia R34 was constructed as follows. First, each of the 3 segments of the DNT pathway was separately amplified from strain R34 by PCR. $d n t R$ and $d n t A_{a b c d}$ genes $(6.2 \mathrm{~kb})$ were amplified with 5'-AGCTGAATTCTTGCT GGACGCTTATGCT-3' and 5'-TTAATCTAGACCAGGGCTCACAGGAAG AT-3' primers; dntDEG genes ( 4.5 kb) were amplified with 5'-TTAATCTAGACTGATTCGTTCTCGCTCCAT-3' and 5'-AGC TACTAGTGCCTCAAGTGACCTCTTTGG-3' primers. Finally, the $d n t B$ gene ( $1.8 \mathrm{~kb})$ was amplified with 5 '-GAACTCTAGAAACGAGACGGCACGATTTT-3' and 5'-TTAATCTAGACTGGGAAGAACCAT TTAGGC-3' primers. PCR reactions were run with high fidelity proof-reading polymerase (Phusion ${ }^{\mathrm{TM}}$ ) in the following conditions: pre-denaturation at $98^{\circ} \mathrm{C}$ for $2 \mathrm{~min}, 30$ cycles with denaturation at $98{ }^{\circ} \mathrm{C}$ for 15 $\mathrm{sec}$, annealing at $60{ }^{\circ} \mathrm{C}$ for $30 \mathrm{~s}$, extension at $72{ }^{\circ} \mathrm{C}(3 \mathrm{~min}$ for $6.2 \mathrm{~kb}$ fragment, 2 min for $4.5 \mathrm{~kb}$ and 1 min for $1.8 \mathrm{~kb}$ ) with a final extension at $72^{\circ} \mathrm{C}$ for $10 \mathrm{~min}$. Plasmid pSEVA651 was cleaved with EcoRI and $X b a l$ and then ligated with the DNA fragment that contained $d n t R$ and $d n t A_{a b c d}$ genes. After confirmation by sequencing, the resulting plasmid was cut with Xbal and Spel and then ligated to the fragment that contained the $d n t D E G$ genes. Finally, the PCR product with the $d n t B$ gene was digested with $\mathrm{Xbal}$ and cloned into the same site of the resulting vector. Clones were first checked by colony PCR using GoTaq polymerase and later confirmed by DNA sequencing. The constructed plasmid was named pSEVA_dnt (Fig. 1B).

\section{Construction of transcriptional reporters}

A transcriptional reporter fusion responsive to DNA damage was constructed by directional cloning of the PCR-amplified promoter region of the recA gene of $E$. coli MG1655 into the multiple cloning site of the promoterless GFP-luxCDABE vector, pGLR2 (Benedetti et al., 2012) using as a reference the DNA sequence of the NCBI database (https://www.ncbi.nlm.nih.gov/). To this end, PCR primers (5'-GCG CGAATTCCCGCGGTGAAGGCATTACC-3' and 5'-GCGCGGATCCGCCGGGTAATACCGGATAGTC3') were designed for flanking the PrecA promoter with EcoRI and BamHI sites. Purified PCR products and vector DNA were digested with BamHI and EcoRI, ligated and transformed into E. coli DH5a prior to plating on Km-LB medium. The plasmid borne by positive transformants was confirmed PCR and 
DNA sequence analysis. A similar strategy was followed for constructing transcriptional fusions of the promoters of two oxidative stress marker genes, i.e., ahpC (alkyl hydroperoxide reductase) and katG [catalase/hydroperoxidase $\mathrm{HPI}(\mathrm{I})$ ] to msfGFP. In one case, the region -359 to -10 of the ahpC gene was amplified as an EcoRI-BamHI DNA fragment with primers ahpC-EcoRI-FW (5'-ATCGGAATTCAG TCAGTGCAAAAG CG-3') and ahpC-BamHI-RV (5'-AGTCGGATCCGTGTTTTCGATGAGATG-3'). The PCR product was then digested with these enzymes and cloned in the corresponding sites of the pRK2based broad-host-range vector pSEVA227M in front of a promoterless msfGFP gene (Silva-Rocha et al., 2013). By the same token, the region -163 to -2 upstream of the katG gene was amplified with primers katG-EcoRI-FW (5'-GTCCGAATTCGGACATAATCAAAA A-3') and katG-BamHI-RV (5'-AGT CGGATCCAATGTGCTCCCCTCTAC A-3') and cloned in the same vector pSEVA227M as before. These operations finally yielded plasmids pGLR2-PrecA, $\mathrm{p} \_$ahpC and $\mathrm{p} \_$katG (Table 1).

\section{Metrology of fluorescent reporters}

For quantification of GFP readouts, E. coli strains carrying the constructs indicated in each case were grown in filtered LB medium up to an $\mathrm{OD}_{600} \sim 0.5$ and added with DNT $(0.5 \mathrm{mM})$, NOR $(250 \mathrm{ng} / \mathrm{ml})$ or CIP $(100 \mathrm{ng} / \mathrm{ml})$ as specified in the corresponding experiment. After a time of exposure to the specific additions, the cells of $1 \mathrm{ml}$ culture aliquots were spun down and washed three times with filtered $1 \times \mathrm{PBS}$ $\left(8 \mathrm{~g} \mathrm{l}^{-1} \mathrm{NaCl}, 0.2 \mathrm{~g} \mathrm{l}^{-1} \mathrm{KCl}, 1.4 \mathrm{~g} \mathrm{l}^{-1} \mathrm{Na}_{2} \mathrm{HPO} 4\right.$, and $\left.0.2 \mathrm{~g} \mathrm{l}^{-1} \mathrm{KH}_{2} \mathrm{PO} 4, \mathrm{pH} 7.4\right)$, and re-suspended in 1× PBS. Single-cell GFP fluorescence was excited at $488 \mathrm{~nm}$ and recovered with a $525 \pm 40 \mathrm{~nm}$ band pass filter in a MACSQuant VYB flow cytometer (Miltenyi) as explained in (Martinez-Garcia et al., 2014). At least 15000 cells were analyzed for every aliquot. Induction of the reporter product under the conditions tested was measured by first gating the bacteria in a side-scatter vs. forward-scatter plot, and then the GFP-associated fluorescence was recorded in the FL1 channel (515-545 nm). Data processing was done with a FlowJoTM software (FlowJo LLC, Ashland, OR, USA). ROS sensitive green fluorescent dye 2,7-dichlorodihydrofluorescein diacetate $\left(\mathrm{H}_{2} \mathrm{DCF}-\mathrm{DA}\right.$; Sigma-Aldrich Co.) was used to quantify intracellular ROS production in E. coli. For this, cells were grown to the desired stage and treated overnight with DNT. Bacteria of $1 \mathrm{ml}$ of culture were then pelleted and washed twice with PBS $\mathrm{pH}=7.5$ and resuspended in the same buffer to adjust the $\mathrm{OD}_{600} \sim 0.4$. Samples were added with $20 \mu \mathrm{M}$ H2DCF-DA and incubated in the dark for $30 \mathrm{~min}$ at room temperature. Bacteria were next washed twice 
with PBS to remove unbound label, resuspended again and analyzed by flow cytometry. The H2DCFDA fluorescence emission at $525 \mathrm{~nm}$ was detected using a $530 \pm 30$-nm band pass filter array.

Determination of mutants frequency and analysis of RifR clones

E. coli cultures were grown overnight in LB with appropriate antibiotics for retaining the plasmids. Samples were then diluted $10^{5}$-fold into fresh same medium containing either $0.5 \mathrm{mM}$ DNT or DMSO and incubated with vigorous shaking for $24-\mathrm{h}$ at $37^{\circ} \mathrm{C}$. Appropriate dilutions of cells were spread on LB plates containing $100 \mu \mathrm{g} / \mathrm{ml}$ of rifampicin and colony count done after $24 \mathrm{~h}$ of growth. To have a reliable statistics, each of these CFU-counting experiments was repeated 3-times with 4 technical replicates. Mutants frequency values are reported as the dimensionless ratio between the number of RifR colonies and the total viable count (Rosche and Foster, 2000). In order to molecular analyze the types of mutations induced at the rpoB gene locus by DNT in $E$. coli cells, individual RifR mutants were reisolated, resuspended in $50 \mu \mathrm{L}$ of deionized water and vortexed vigorously to release some cellular DNA. $2 \mu \mathrm{L}$ of the suspensions were used as the template of a PCR reaction with primers 5 'TGGCCTGGTACGTGT AGA-3' and 5'-AACCAGCGGCTTATCAGC-3' for amplifying a region of the $r p o B$ gene known to cluster mutations resulting in the RifR phenotype (Kalapila et al., 2008). The 700 base pairs PCR products were purified with the ExoSAP-ITTM PCR product clean-up kit (USB, Affymetrix Ltd., Santa Clara, CA, USA) and sequenced with the same primers used for amplification.

\section{Measurement of recombinogenic activity}

Recombination frequencies were studied as described (Elez et al., 2007; Lopez et al., 2007). Bacterial cultures of strain E. coli ME12 (Table 1) bearing either the $d n^{+}$plasmid pSEVA_dnt or the insertless vector pSEVA651 were inoculated at a very high dilution ( $<100$ cells) in LB with antibiotics as needed to ensure that no pre-existing LacZ ${ }^{+}$cells were present in the starting inoculum. Cells were then grown overnight at $37^{\circ} \mathrm{C}$, diluted to an $\mathrm{OD}_{600}$ of 0.1 in fresh medium and incubated for one further hour at $37^{\circ} \mathrm{C}$ without shaking. In order to count $\mathrm{Lac}^{+}$recombinants, $2 \mathrm{ml}$ of each culture were added with $0.5 \mathrm{mM}$ DNT and the incubation continued with shaking for the next $4 \mathrm{~h}$. As a control, the plasmid-less strain $E$. coli ME12 was treated with CIP under the same conditions (Lopez et al., 2007). Approximately $10^{8}$ cells from each culture were then added with 10-fold excess of scavenger cells (E. coli NEC222; Table 1) for 
depleting any contaminating non-lactose carbon sources in the medium. The mix was suspended in 3 $\mathrm{ml}$ top agar and adequate dilutions were plated onto M9-lactose Petri dishes. Plates were incubated at $37^{\circ} \mathrm{C}$ for $48 \mathrm{~h}$. X-Gal and IPTG were added to the agar medium to facilitate the visualization of $\mathrm{LacZ}^{+}$ recombinants. Total cell number was determined by plating equivalent dilutions of the tested strains-only on $\mathrm{M} 9$ medium with glucose as carbon source $(0.2 \% \mathrm{w} / \mathrm{v})$.

Acknowledgements. Jesús Blázquez (CNB-CSIC) is gratefully acknowledged for his crucial advice on bacterial mechanisms of evolvability and critical reading of the manuscript. Authors thank also Enrique Vigera (University of Malaga) and Ivan Matic (TaMaRa Laboratory, France) for their generous sharing of strains. This study was supported by HELIOS Project of the Spanish Ministry of Economy and Competitiveness BIO2015-66960-C3-2-R (MINECO/FEDER), and the ARISYS (ERC-2012-ADG322797), EmPowerPutida (EUH2020-BIOTEC-2014-2015-6335536), and MADONNA (H2020-FETOPEN-RIA-2017-1-766975) contracts of the European Union to V.D.L. O.A. was supported by TUBITAK-BIDEB through the International Postdoctoral Research Scholarship Programme 2219. P.I.N gratefully acknowledges The Novo Nordisk Foundation and the Danish Council for Independent Research for grants NNF10CC1016517 and SWEET, DFF-Research Project 8021-00039B, respectively. D.P.-P also thanks the support of the Chilean government through Grant CONICYT/PIA Anillo ACT172128 and Grant FONDECYT 1161750.

\section{REFERENCES}

Akkaya, O., Pérez-Pantoja, D., Calles, B., Nikel, P.I., and de Lorenzo, V. (2018) The metabolic redox regime of $P$ seudomonas putida tunes its evolvability towards novel xenobiotic substrates. $m B$ io (In Press).

Andersson, D.I., and Hughes, D. (2014) Microbiological effects of sublethal levels of antibiotics. Nat Rev Microbiol 12: 465-478.

Baba, T., Ara, T., Hasegawa, M., Takai, Y., Okumura, Y., Baba, M. et al. (2006) Construction of Escherichia coli K- 12 in- frame, single- gene knockout mutants: the Keio collection. Mol Sys Biol 2: 2006.0008 . 
Becerra, M.C., Eraso, A.J., and Albesa, I. (2003) Comparison of oxidative stress induced by ciprofloxacin and pyoverdin in bacteria and in leukocytes to evaluate toxicity. Luminescence 18: 334-340.

Benedetti, I.M., de Lorenzo, V., and Silva-Rocha, R. (2012) Quantitative, non-disruptive monitoring of transcription in single cells with a broad-host range GFP-luxCDABE dual reporter system. PLoS One 7: e52000.

Blattner, F.R., Plunkett, G., 3rd, Bloch, C.A., Perna, N.T., Burland, V., Riley, M. et al. (1997) The complete genome sequence of Escherichia coli K-12. Science 277: 1453-1462.

Blazquez, J., Rodrıguez-Beltran, J., and Matic, I. (2018) Antibiotic-induced genetic variation: How It arises and how it can be prevented. Ann Rev Microbiol 72: 209-230.

Bolin, C., and Cardozo-Pelaez, F. (2007) Assessing biomarkers of oxidative stress: Analysis of guanosine and oxidized guanosine nucleotide triphosphates by high performance liquid chromatography with electrochemical detection. J Chrom B 856: 121-130.

Chen, J., and Gottesman, S. (2017) Hfq links translation repression to stress-induced mutagenesis in $E$. coli. Genes Dev 31: 1382-1395.

Dapa, T., Fleurier, S., Bredeche, M.F., and Matic, I. (2017) The SOS and RpoS regulons contribute to bacterial cell robustness to genotoxic stress by synergistically regulating DNA polymerase Pol II. Genetics 206: 1349-1360.

Datsenko, K.A., and Wanner, B.L. (2000) One-step inactivation of chromosomal genes in Escherichia coli K-12 using PCR products. Proc Natl Acad Sci U S A 97: 6640-6645.

de Las Heras, A., Chavarria, M., and de Lorenzo, V. (2011) Association of dnt genes of Burkholderia sp. DNT with the substrate-blind regulator DntR draws the evolutionary itinerary of 2,4-dinitrotoluene biodegradation. Mol Microbiol 82: 287-299.

Elez, M., Radman, M., and Matic, I. (2007) The frequency and structure of recombinant products is determined by the cellular level of MutL. Proc Natl Acad Sci USA 104: 8935-8940.

Foster, P.L. (2005) Stress responses and genetic variation in bacteria. Mutation Res 569: 3-11.

Galhardo, R.S., Do, R., Yamada, M., Friedberg, E.C., Hastings, P.J., Nohmi, T., and Rosenberg, S.M. (2009) DinB upregulation is the sole role of the SOS response in stress-induced mutagenesis in Escherichia coli. Genetics 182: 55-68. 
Gullberg, E., Cao, S., Berg, O.G., Ilback, C., Sandegren, L., Hughes, D., and Andersson, D.I. (2011) Selection of resistant bacteria at very low antibiotic concentrations. PLoS Pathog 7: e1002158.

Gutierrez, A., Laureti, L., Crussard, S., Abida, H., Rodriguez-Rojas, A., Blazquez, J. et al. (2013) betaLactam antibiotics promote bacterial mutagenesis via an RpoS-mediated reduction in replication fidelity. Nat Commun 4: 1610.

Hanahan, D., and Meselson, M. (1983) Plasmid screening at high colony density. Methods Enzymol 100: 333-342.

Hastings, P.J., Hersh, M.N., Thornton, P.C., Fonville, N.C., Slack, A., Frisch, R.L. et al. (2010) Competition of Escherichia coli DNA polymerases I, II and III with DNA Pol IV in stressed cells. PLoS One 5: e10862.

Herrero, M., de Lorenzo, V., and Timmis, K.N. (1990) Transposon vectors containing non-antibiotic resistance selection markers for cloning and stable chromosomal insertion of foreign genes in Gram-negative bacteria. J Bacteriol 172: 6557-6567.

Ilmjarv, T., Naanuri, E., and Kivisaar, M. (2017) Contribution of increased mutagenesis to the evolution of pollutants-degrading indigenous bacteria. PLoS One 12: e0182484.

Johnson, G.R., and Spain, J.C. (2003) Evolution of catabolic pathways for synthetic compounds: bacterial pathways for degradation of 2,4-dinitrotoluene and nitrobenzene. Appl Microbiol Biotechnol 62: 110-123.

Johnson, G.R., Jain, R.K., and Spain, J.C. (2002) Origins of the 2,4-dinitrotoluene pathway. J Bacteriol 184: 4219-4232.

Ju, K.S., and Parales, R.E. (2010) Nitroaromatic compounds, from synthesis to biodegradation. Microbiol Mol Biol Rev 74: 250-272.

Kalapila, A.G., Loktionova, N.A., and Pegg, A.E. (2008) Alkyltransferase-mediated toxicity of 1,3butadiene diepoxide. Chem Res Toxicol 21: 1851-1861.

Kessinger, T.A., and Van Cleve, J. (2018) Genetic draft and valley crossing. bioRxiv. doi: http://dx.doi.org/10.1101/383737

Kohanski, M.A., DePristo, M.A., and Collins, J.J. (2010) Sublethal antibiotic treatment leads to multidrug resistance via radical-induced mutagenesis. Mol Cell 37: 311-320.

Kovacic, P., and Somanathan, R. (2014) Nitroaromatic compounds: Environmental toxicity, carcinogenicity, mutagenicity, therapy and mechanism. J App/ Toxicol 34: 810-824. 
Krisko, A., and Radman, M. (2013) Phenotypic and genetic consequences of protein damage. PLoS Genet 9: e1003810.

Layton, J.C., and Foster, P.L. (2003) Error-prone DNA polymerase IV is controlled by the stressresponse sigma factor, RpoS, in Escherichia coli. Mol Microbiol 50: 549-561.

Li, G.-M. (2008) Mechanisms and functions of DNA mismatch repair. Cell Res 18: 85.

Lopez, E., and Blazquez, J. (2009) Effect of subinhibitory concentrations of antibiotics on intrachromosomal homologous recombination in Escherichia coli. Antimicrob Agents Chemother 53: 3411-3415.

Lopez, E., Elez, M., Matic, I., and Blazquez, J. (2007) Antibiotic-mediated recombination: ciprofloxacin stimulates SOS-independent recombination of divergent sequences in Escherichia coli. Mol Microbiol 64: 83-93.

Martinez-Garcia, E., Aparicio, T., de Lorenzo, V., and Nikel, P.I. (2014) New transposon tools tailored for metabolic engineering of Gram-negative microbial cell factories. Front Bioeng Biotechnol 2: 46.

Michel, B. (2005) After 30 years of study, the bacterial SOS response still surprises us. PLoS Biol 3: e255.

Nikel, P.I., Perez-Pantoja, D., and de Lorenzo, V. (2013) Why are chlorinated pollutants so difficult to degrade aerobically? Redox stress limits 1,3-dichloroprop-1-ene metabolism by Pseudomonas pavonaceae. Philos Trans R Soc Lond B Biol Sci 368: 20120377.

Nishino, S.F., Paoli, G.C., and Spain, J.C. (2000) Aerobic degradation of dinitrotoluenes and pathway for bacterial degradation of 2,6-dinitrotoluene. Appl Environ Microbio/ 66: 2139-2147.

Perez-Pantoja, D., Nikel, P.I., Chavarria, M., and de Lorenzo, V. (2013) Endogenous stress caused by faulty oxidation reactions fosters evolution of 2,4-dinitrotoluene-degrading bacteria. PLoS Genet 9: e1003764.

Phillips, I., Culebras, E., Moreno, F., and Baquero, F. (1987) Induction of the SOS response by new 4quinolones. J Antimicrob Chemother 20: 631-638.

Piddock, L.J.V., and Wise, R. (1987) Induction of the SOS response in Escherichia coli by 4-quinolone antimicrobial agents. FEMS Microbiol Lett 41: 289-294.

Rosche, W.A., and Foster, P.L. (2000) Determining mutation rates in bacterial populations. Methods 20: 4-17. 
Sambrook, J., Fritsch, E.F., and Maniatis, T. (1989) Molecular cloning: a laboratory manual: Cold Spring Harbor Laboratory Press.

Sikkema, J., de Bont, J.A., and Poolman, B. (1995) Mechanisms of membrane toxicity of hydrocarbons. Microbiol Rev 59: 201-222.

Silva-Rocha, R., Martinez-Garcia, E., Calles, B., Chavarria, M., Arce-Rodriguez, A., de Las Heras, A. et al. (2013) The Standard European Vector Architecture (SEVA): a coherent platform for the analysis and deployment of complex prokaryotic phenotypes. Nucleic Acids Res 41: D666-675.

Spanggord, R.J., Spain, J.C., Nishino, S.F., and Mortelmans, K.E. (1991) Biodegradation of 2,4dinitrotoluene by a Pseudomonas sp. Appl Environ Microbiol 57: 3200-3205.

Suen, W.C., Haigler, B.E., and Spain, J.C. (1996) 2,4-Dinitrotoluene dioxygenase from Burkholderia sp. strain DNT: similarity to naphthalene dioxygenase. J Bacteriol 178: 4926-4934.

Tenaillon, O., Denamur, E., and Matic, I. (2004) Evolutionary significance of stress-induced mutagenesis in bacteria. Trends Microbiol 12: 264-270.

Veaute, X., Delmas, S., Selva, M., Jeusset, J., Le Cam, E., Matic, I. et al. (2005) UvrD helicase, unlike Rep helicase, dismantles RecA nucleoprotein filaments in Escherichia coli. EMBO J 24: 180-189. 


\begin{tabular}{|c|c|c|}
\hline Strains & Description/relevant characteristics & Reference \\
\hline B. cepacia R34 & $\begin{array}{l}\text { DNT-degrading strain carrying pJS311 and pJS312 } \\
\text { megaplasmids }\end{array}$ & $\begin{array}{l}\text { (Nishino et al., } \\
2000)\end{array}$ \\
\hline E. coli DH5a & $\begin{array}{l}\text { supE44,DlacU169 (f80 lacZDM15), hsdR17 (rk- } \\
m k+), r e c A 1, \text { endA1, thi1, gyrA, relA }\end{array}$ & $\begin{array}{l}\text { (Hanahan and } \\
\text { Meselson, 1983) }\end{array}$ \\
\hline CC118 & $\begin{array}{l}\mathrm{F}^{-}, \Delta(\text { ara-leu) } 7697, \text { araD139, } \Delta \text { (lac)X74, phoA } \Delta 20, \text { ale, } \\
\text { galK, thi, rpsE, rpoB }\end{array}$ & $\begin{array}{l}\text { (Herrero et al., } \\
\text { 1990) }\end{array}$ \\
\hline MG1655 & Wild-type strain; $F^{-} \lambda^{-} r p h-1$ & $\begin{array}{l}\text { (Blattner et al., } \\
\text { 1997) }\end{array}$ \\
\hline BW25113 & $\begin{array}{l}\text { Wild-type strain; } F^{-} \lambda-\Delta(a r a D \text {-araB)567 } \Delta l a c Z 4787(: r r n B-3) \\
r p h-1 \Delta(r h a D \text { rhaB }) 568 \text { hsdR514 }\end{array}$ & $\begin{array}{l}\text { (Datsenko and } \\
\text { Wanner, 2000) }\end{array}$ \\
\hline JW2669-1 & Same as BW25113, but $\Delta r e c A:: k a n$ & (Baba et al., 2006) \\
\hline JW1173-1 & Same as BW25113, but $\Delta u m u C::$ kan & (Baba et al., 2006) \\
\hline JW5437-1 & Same as BW25113, but $\Delta r p o S::$ kan & (Baba et al., 2006) \\
\hline JW0941-1 & Same as BW25113, but $\Delta s u l A::$ kan & (Baba et al., 2006) \\
\hline JW0221-1 & Same as BW25113, but $\Delta$ dinB::kan & (Baba et al., 2006) \\
\hline ME12 & $\begin{array}{l}\text { Same as MG1655, but containing identical repeats of } \\
\text { truncated lacZ genes }\end{array}$ & (Baba et al., 2006) \\
\hline NEC222 & $\begin{array}{l}\text { Same as MG1655, but } \Delta C \text { lacZ::cat. Scavenger strain for } \\
\text { consumption of } C \text { sources other than lactose }\end{array}$ & $\begin{array}{l}\text { (Veaute et al., } \\
\text { 2005) }\end{array}$ \\
\hline Plasmids & Description/relevant characteristics* & Reference \\
\hline pSEVA651 & $\begin{array}{l}\text { Gm } \text {, RSF1010, oriT; standard broad-host-range plasmid } \\
\text { for Gram-negative bacteria }\end{array}$ & $\begin{array}{l}\text { (Silva-Rocha et al., } \\
\text { 2013) }\end{array}$ \\
\hline pSEVA227M & $\begin{array}{l}\mathrm{Km} \text {, RK2-based low-copy number vector for construction } \\
\text { of transcriptional fusions to msfGFP }\end{array}$ & $\begin{array}{l}\text { (Silva-Rocha et al., } \\
\text { 2013) }\end{array}$ \\
\hline p_katG & $\begin{array}{l}\mathrm{Km} \text { R, RK2-based, low-copy number plasmid, pSEVA227M } \\
\text { containing promoter region of katG }\end{array}$ & This work \\
\hline p_ahpC & $\begin{array}{l}\mathrm{Km}^{\mathrm{R}} \text {, RK2-based, low-copy number plasmid, pSEVA227M } \\
\text { containing promoter region of ahpC }\end{array}$ & This work \\
\hline pSEVA_dnt & $\begin{array}{l}\mathrm{Gm}^{\mathrm{R}} \text {, oriV R6K, oriT; pSEVA651 derivative inserted with } \\
\text { dnt gene cluster (dntAabcdBDEG) from B. cepacia R34 }\end{array}$ & This work \\
\hline
\end{tabular}




\begin{tabular}{|l|l|l|}
\hline pGLR2 & $\begin{array}{l}\mathrm{Km}{ }^{\mathrm{R}} \text {, oriT, RK2-based, low-copy number vector for making } \\
\text { bicistronic GFP/lux reporter fusions }\end{array}$ & $\begin{array}{l}\text { (Benedetti et al., } \\
\text { 2012) }\end{array}$ \\
\hline pGLR2-PrecA & $\begin{array}{l}\mathrm{Km} \text {, pGLR2 inserted with the PrecA promoter of } E \text {. coli as } \\
\text { a EcoRI/BamHI fragment }\end{array}$ & \begin{tabular}{l} 
This work \\
\hline
\end{tabular} \\
\hline
\end{tabular}

*Abbreviations: Km, kanamycin; Gm, gentamycin 


\section{LEGENDS TO FIGURES}

Figure 1. DNT mineralization pathway of B. cepacia R34. (A) Key biochemical steps for DNT catabolism. The DNT catabolic route starts with the DntA DNT dioxygenase that hydroxylates the aromatic ring in positions 4 and 5 to yield 4-methyl-5-nitrocatechol (4M5NC), releasing, at the same time, the first nitro substituent. The resulting catechol is subsequently mono-oxygenated by the DntB hydroxylase, that eliminates the remaining nitro group in the structure, thereby producing 2-hydroxy-5methylquinone (2H5MQ). The rest of the pathway (executed by DntCDGE) includes a ring cleavage reaction and channelling of the products towards the central metabolism. Note that DntC is an unspecific quinone reductase in B. cepacia. (B) Arrangement of the dnt genes and their reassembly as a single DNA fragment. The figure sketches the organization and composition of the 3 genetic segments involved in DNT degradation: $d n t R / d n t A a b c d$ (blue), $d n t B$ (green) and $d n t D E G$ (orange) as assembled in plasmid pSEVA_dnt. Note that the functional genes are accompanied of ORFs of unknown function (in grey) and a regulator (dntR) blind to the pathway substrate. (C) Accumulation of 4M5NC in E. coli BW25113 (pSEVA_dnt) exposed to DNT. Cultures of the $d n t^{+}$strain in M9-0.4\% succinate were added (or not) with $0.5 \mathrm{mM}$ DNT for $3 \mathrm{~h}$, after a yellow metabolite became evident. As shown, the UV-visible scanning of the raw supernatants produced a single maximum absorption peak at $420 \mathrm{~nm}$ that was missing in the control culture without DNT, which corresponds to 4M5NC (Nishino et al., 2000; de Las Heras et al., 2011).

Figure 2. Generation of ROS in DNT-metabolizing E. coli cells exposed to DNT. (A) Distribution of dichlorofluorescein (DCF) fluorescence in bacteria metabolizing DNT. Cells of $d n t^{+} E$. coli BW25113 (pSEVA_dnt) strain and the dnt-minus control E. coli BW25113 (pSEVA651) were treated for $16 \mathrm{~h}$ with either DMSO (green) or 0.5 mM DNT (red). Formation of ROS was measured with the ROS-sensitive probe H2DCF-DA, which becomes transformed upon oxidation into green-emitting dichlorofluorescein (DCF). Fluorescence of at least 20,000 individual cells in arbitrary units (A.U.) was recorded as previously described (Nikel et al., 2013). (B) Histograms replot the data from cells exposed to either DMSO (green) or $0.5 \mathrm{mM}$ DNT (red). The values shown are the mean of three independent experiments. 
Figure 3. Oxidative stress caused by DNT metabolism in E. coli BW25113 (pSEVA_dnt). (A) Organization of reporter plasmids. The sketch of the constructs shows the promoter regions of either katG (catalase) or ahpC (alkyl hydroperoxide reductase) genes in front of a promoterless msfGFP reporter and assembled in a broad host range, $\mathrm{Km}^{\mathrm{R}}$ low copy number vector which is compatible with the antibiotic marker and the replication origin of pSEVA_dnt. (B) Induction of katG and ahpC promoters following exposure to $100 \mathrm{ng} / \mathrm{ml}$ CIP (control, red), $0.5 \mathrm{mM}$ DNT (grey) and $0.8 \mathrm{mM}$ DNT (pink). GFP readout was measured $16 \mathrm{~h}$ after additions. Samples were analysed by flow cytometry and signal normalized in respect to GFP intensity of the same untreated strains. The data shown are the mean of three independent experiments.

Figure 4. Stress-induced recombination in cells metabolizing DNT. (A-C) show the rationale of the recombination experiment (Elez et al., 2007; Lopez et al., 2007). A truncated lacZ gene which shares a region of homology with a second truncated segment needed to reconstruct the functional gene is placed in the genome of $E$. coli ME12 separated by a 569-bp DNA spacer. Homologous recombination events originate $\mathrm{Lac}^{+}$clones that give rise to colonies in a minimal medium with lactose. (D) Effect of DNT on recombination frequencies in $d n t^{+}$and dnt-minus $E$. coli ME12 strains. A plasmid-less strain was treated with CIP as a SOS-dependent recombination control. Fold-increase indicates the rise in the appearance of $\mathrm{Lac}^{+}$colonies in respect to controls without additions. Standard deviations of 5 separate experiments for each of the strains and conditions are indicated (in all cases: $p<0.05$ ).

Figure. 5. SOS-induction test in cells degrading DNT. (A) Organization of the PrecA reporter fusion. The sketch shows the business part of the reporter plasmid with the promoter region of the $r e c A$ gene in front of the promoterless GFP/lux part of vector pGLR2 (Benedetti et al., 2012). (B) Flow cytometry of $E$. coli BW25113 cells co-transformed with pGLR2-PrecA and pSEVA_dnt following treatment with DNT for $4 \mathrm{~h}$ and $16 \mathrm{~h}$. The same cells were separately treated with NOR as a SOS-inducing control. Standard deviations of 3 technical replicates for all data points are indicated. (C) Plate visualization of SOSresponse. $100 \mu \mathrm{l}$ of an overnight culture of strain E. coli BW25113 (pGLR2-PrecA + pSEVA_dnt) pregrown in M9-0.4\% succinate were suspended in soft agar and evenly laid on Petri dishes with the same medium and antibiotics for ensuring plasmid retention. Disks soaked with either $5 \mu$ of norfloxacin $5 \mathrm{mg} / \mathrm{ml}$ (control, NOR) or $5 \mu \mathrm{l}$ of $0.5 \mathrm{M}$ DNT were deposited in the centre of the dishes and plates 
incubated for $48 \mathrm{~h}$ at $37^{\circ} \mathrm{C}$. Growth was then visualized under a blue-light lamp. Note production of a fluorescent corona around the inhibition halo produced by NOR—but not DNT.

Figure 6. Spectrum of spontaneous rpoB mutations arising in $E$. coli BW25113(pSEVA_dnt) strain. $E$. coli BW25113 (pSEVA_dnt) strain was grown in LB medium with either DMSO or DNT $(0.5 \mathrm{mM})$ as explained in the text and plated on LB-RifR plates. The DNA sequence of the rpoB gene of 100 colonies of each case was amplified and the range of mutations endowing a RifR phenotype determined. Note that despite very different mutants rates between DNT-added and non-added samples (see text), the profile of nucleotide changes is very similar.

Figure 7. The SOS-dependent and independent routes for stress-induced mutagenesis. Intracellular ROS is able to trigger stress-induced mutagenesis by two different but connected routes. On one hand the occurrence of 8 -oxoguanine $(80 \cdot G)$ resulting from oxidation of $G$ residues. This may damage DNA and trigger the SOS response mediated by RecA protein that cleaves the LexA repressor. As a consequence the error-prone Pol IV enzyme encoded by $\operatorname{din} B$ gene is upregulated. But the $\operatorname{din} B$ gene is also controlled by the alternative sigma factor RpoS, which is also produced at higher levels in cells exposed to oxidative stress. In turn, RpoS increases expression of a small RNA named SdsR that inhibits translation of MutS, thereby reducing mismatch-repair efficiency. Furthermore, the small noncoding RNA ArcZ produced under general stress both increases RpoS translation and decreases that of MutS.

Figure 8. DNT-induced mutagenesis in E. coli BW25113 (pSEVA_dnt) strain and its mutant derivatives. Plasmid pSEVA_dnt was transformed in the wild-type strain E. coli BW25113 as well as in each of the isogenic mutants indicated (Table 1). Transformants were grown for $24 \mathrm{~h}$ in LB with either DMSO (control) or $0.5 \mathrm{mM}$ DNT. The frequency of the rifampicin-resistant mutants in each of the genetic backgrounds was calculated by dividing the average number of RifR colonies by the total number of viable cells in the same culture. Bars represent the average of at least three independent experiments (95\% confidence level; $p<0.05)$. 
(a)
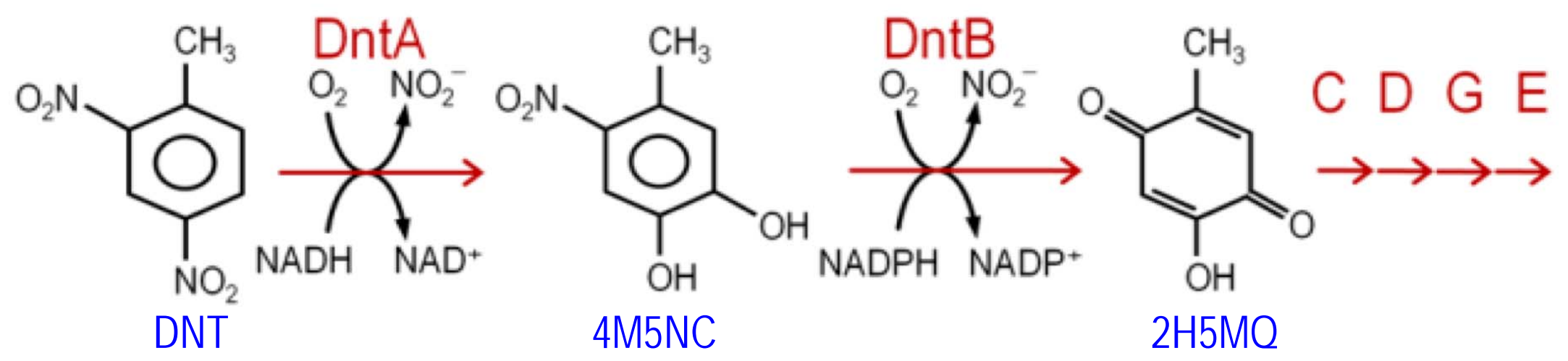

F1

(1) DNT

$4 \mathrm{M} 5 \mathrm{NC}$

(b)

pSEVA_dnt

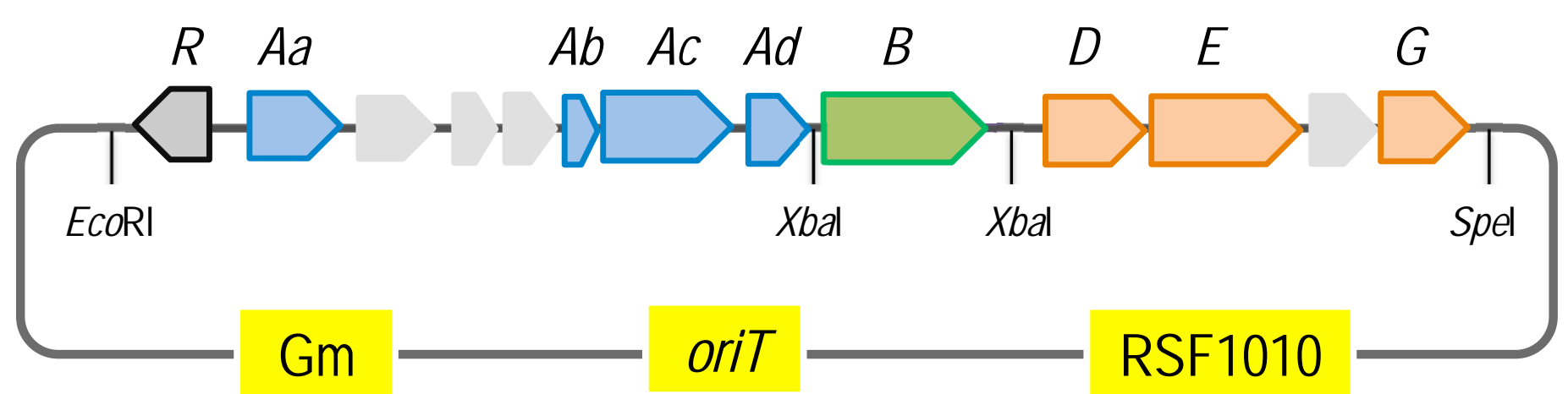

(c)
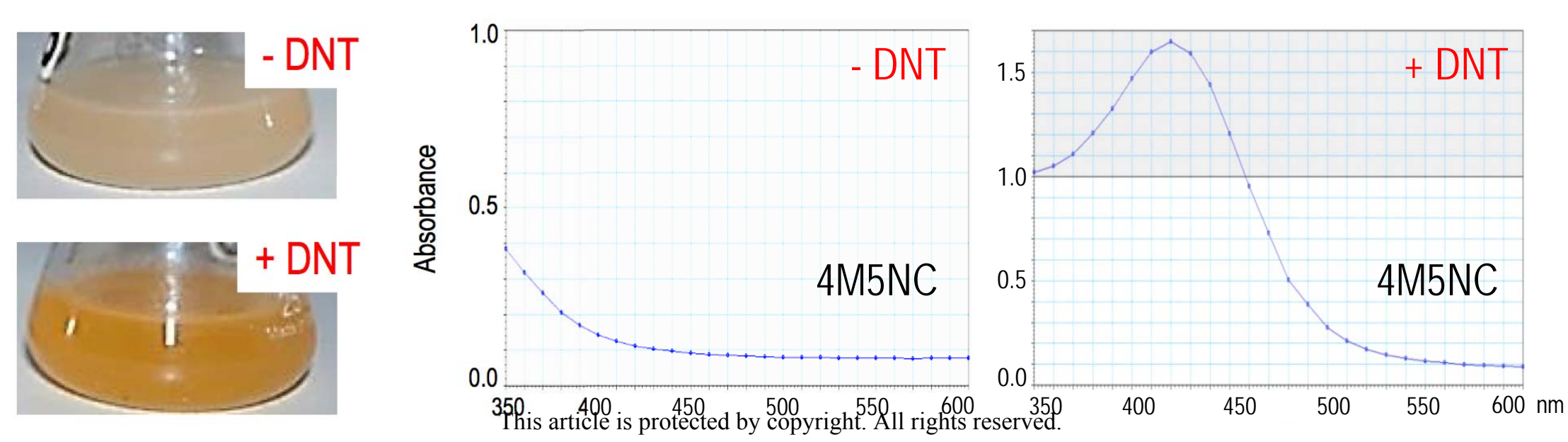

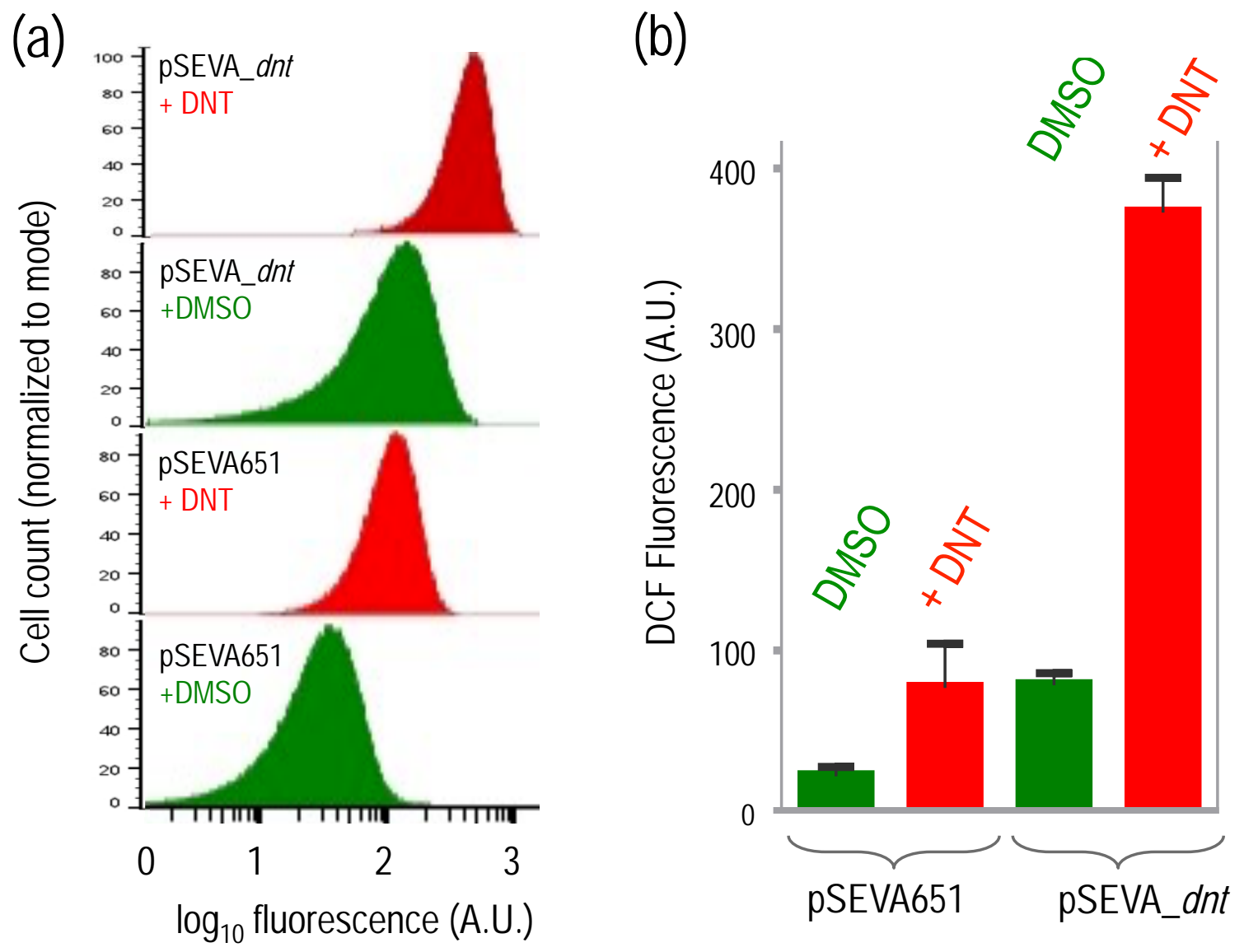
(a) $P_{\text {katG }}$

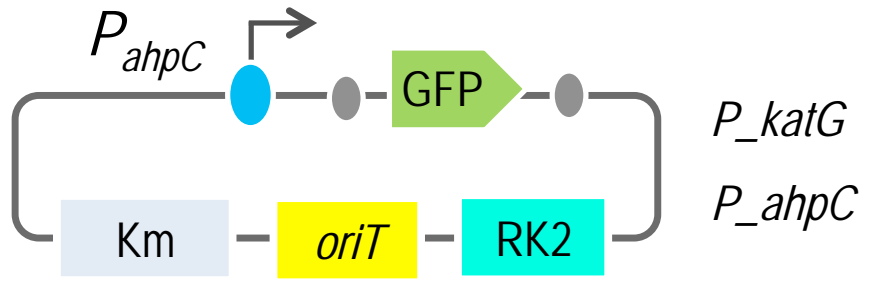

(b)

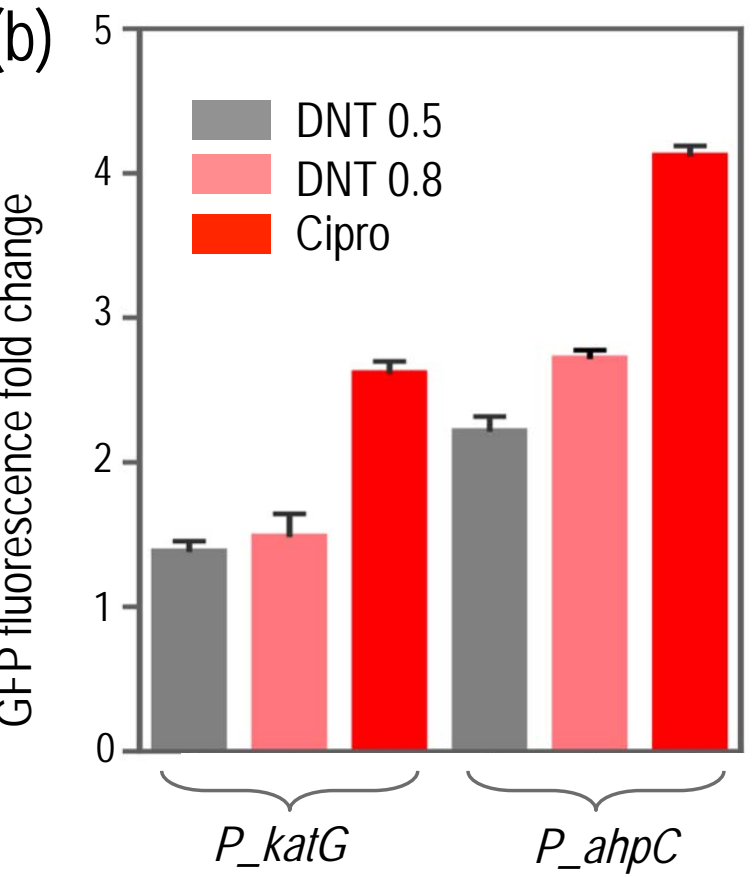

This article is protected by copyright. All rights reserved. 


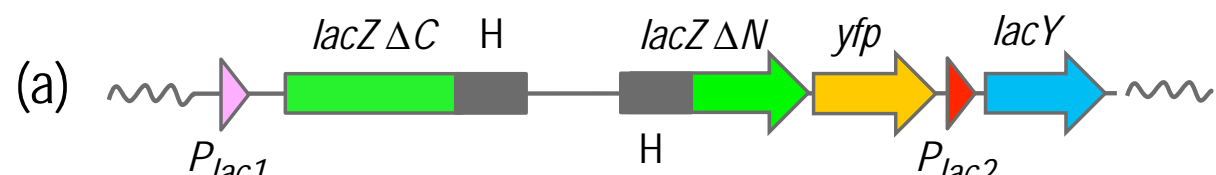

(b) $m-\frac{H}{\square-\ldots, ~} \downarrow$

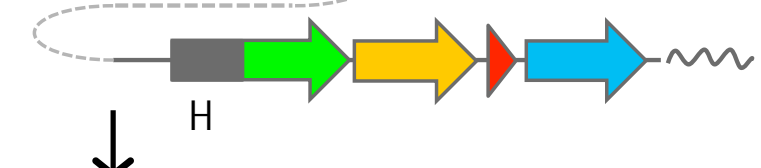

(c) m-

(d) Strain ME12 [lacZ $\Delta C-l a c Z \Delta M]$

Recombination frequency

Fold-increase CIP

Strain $4.7 \times 10^{-3} \pm 4.0 \times 10^{-3}$ $4.8 \pm 0.32$

ME12 (pSEVA651)

Recombination frequency

Fold-increase DNT

ME12 (pSEVA dnt)

$2.2 \times 10^{-3} \pm 1.6 \times 10^{-3}$

$1.7 \pm 0.62$

$4.9 \times 10^{-3} \pm 3.3 \times 10^{-3}$

$1.7 \pm 0.77$ 
(a) Wr-oc GFP - IUxCDABE M

(c)

$\frac{0}{0}$

(b)

b)

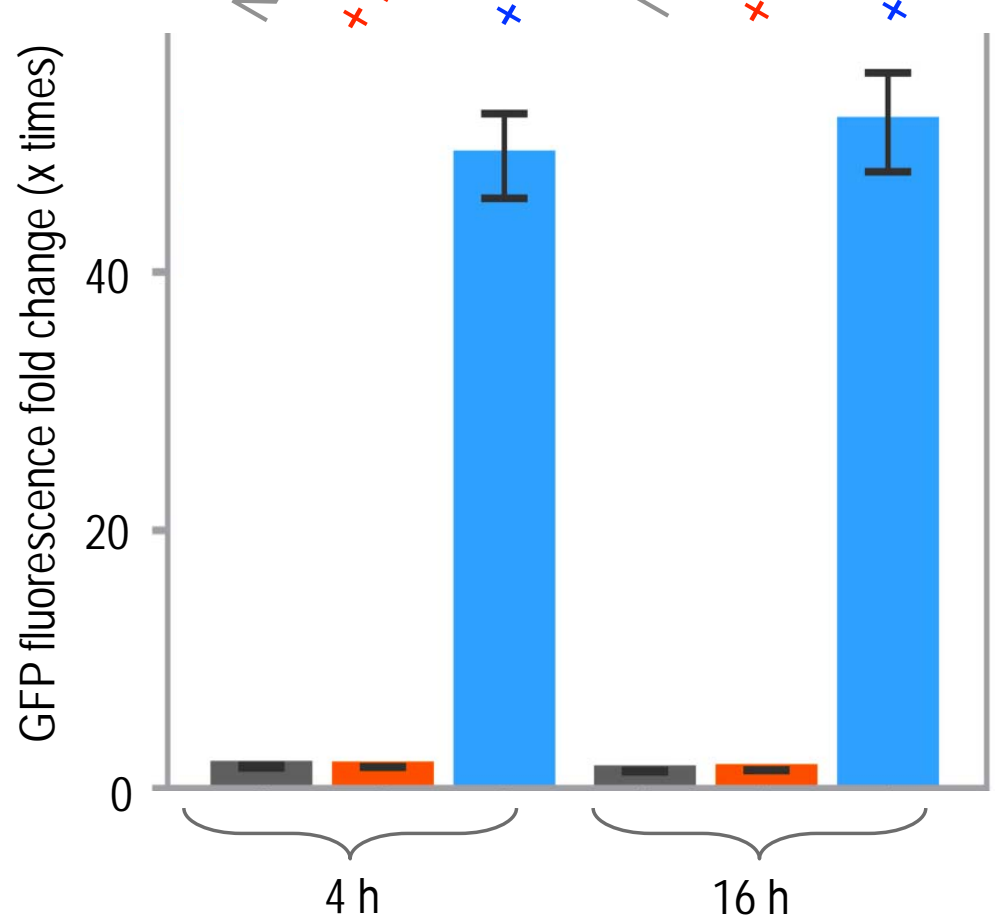

NOR
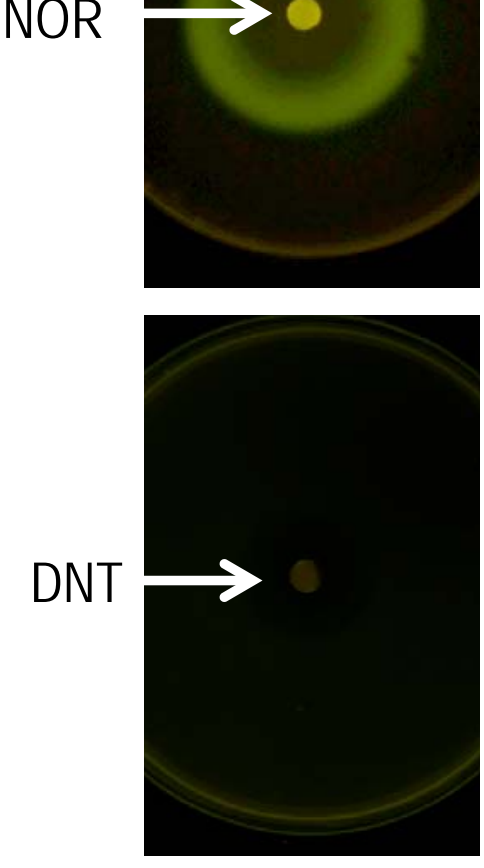


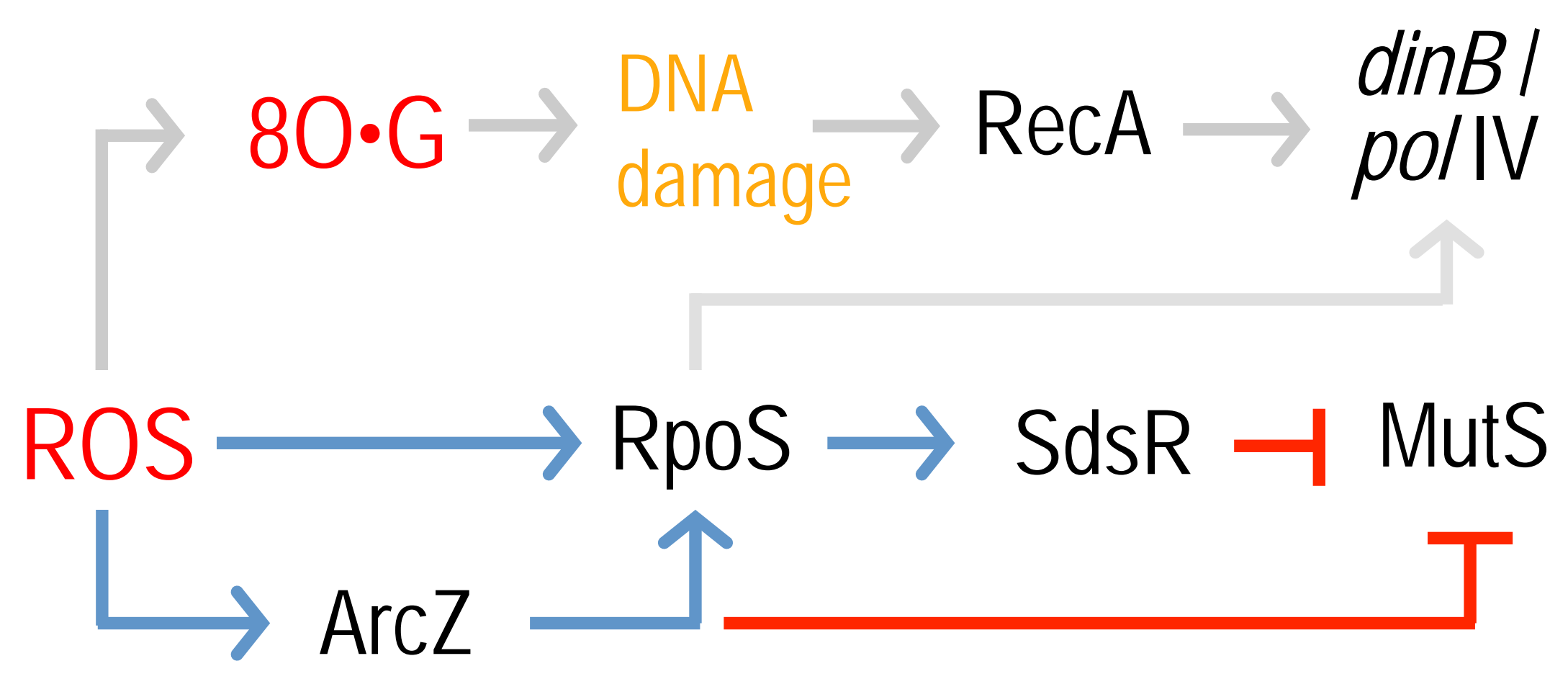




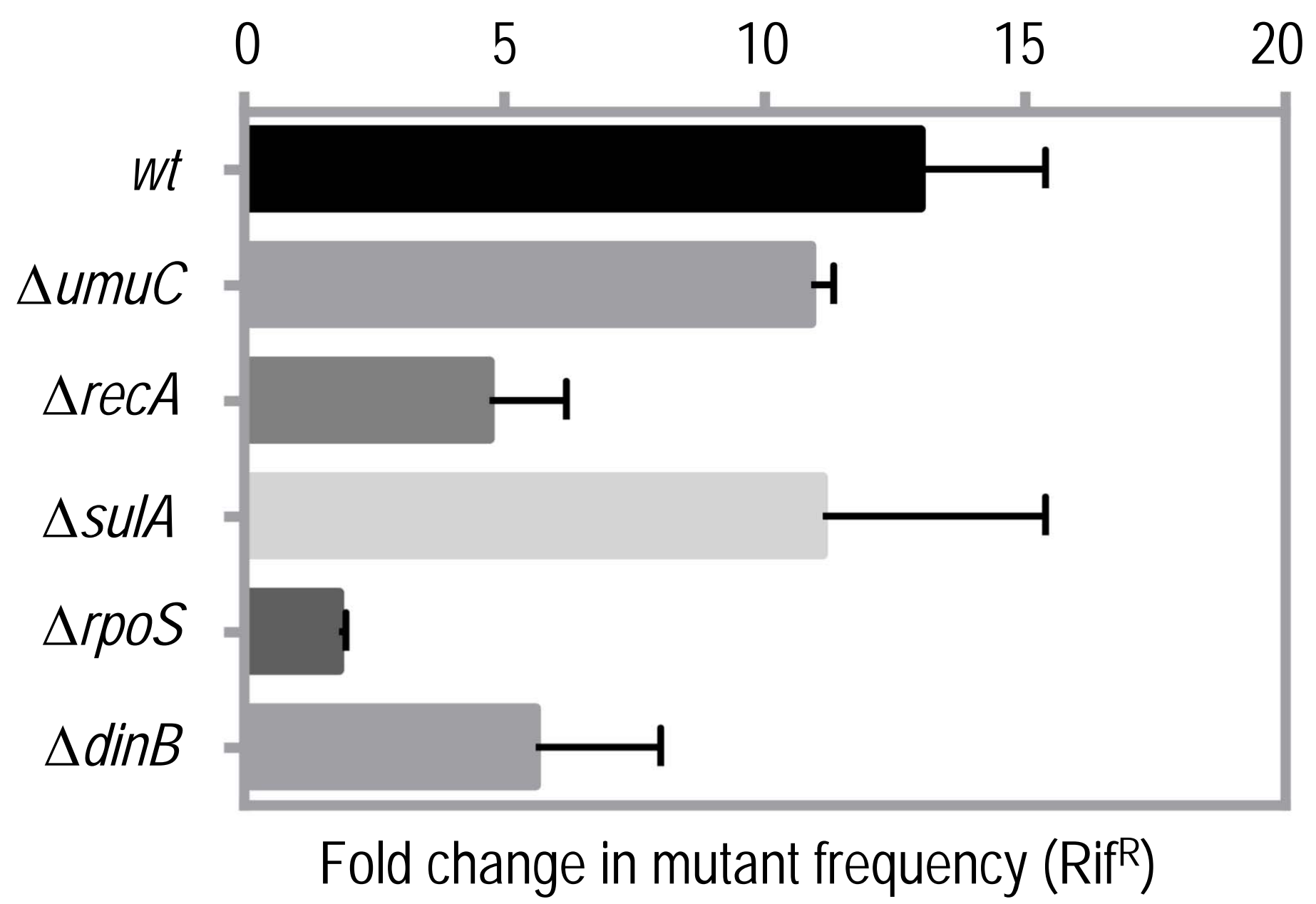

